LAWRENCE LIVERMORE N A TIONAL LABORATORY

\title{
Thermodynamics and Structure of Plutonium Alloys
}

P. G. Allen, P. E. A. Turchi, G. F. Gallegos

February 18, 2004 
This document was prepared as an account of work sponsored by an agency of the United States Government. Neither the United States Government nor the University of California nor any of their employees, makes any warranty, express or implied, or assumes any legal liability or responsibility for the accuracy, completeness, or usefulness of any information, apparatus, product, or process disclosed, or represents that its use would not infringe privately owned rights. Reference herein to any specific commercial product, process, or service by trade name, trademark, manufacturer, or otherwise, does not necessarily constitute or imply its endorsement, recommendation, or favoring by the United States Government or the University of California. The views and opinions of authors expressed herein do not necessarily state or reflect those of the United States Government or the University of California, and shall not be used for advertising or product endorsement purposes.

This work was performed under the auspices of the U.S. Department of Energy by University of California, Lawrence Livermore National Laboratory under Contract W-7405-Eng-48. 


\section{OBJECTIVE}

The goal of this project was to investigate the chemical and structural effects of gallium and impurity elements, iron and nickel, on the phase behavior and crystallography of Pu-Ga alloys. This was done utilizing a theoretical chemical approach to predict binary and ternary alloy energetics, phase stability, and transformations. The modeling results were validated with experimental data derived from the synthesis of selected alloys and advanced characterization tools. The ultimate goal of this work was to develop a robust predictive capability for studying the thermodynamics and the structureproperties relationships in complex materials of high relevance to the Laboratory and DOE misssion.

\section{SUMMARY}

In this three-year project, we investigated the physical and structural origins of phase formation, equilibrium, and stability (e.g., thermodynamics, ordering, phase heterogeneity, and lattice distortions) for a series of plutonium alloys by combining state-of-the-art experimental and theoretical methods.

We performed synthesis of selected binary and ternary alloys containing $\mathrm{Pu}, \mathrm{Ga}, \mathrm{Fe}$, and $\mathrm{Ni}$ at several stoichiometries by melting bulk samples in an inert argon atmosphere. The thermochemistry of the bulk samples was characterized using differential scanning calorimetry (DSC). Bulk structure and elemental distributions (phase heterogeneity and distributions) was studied using scanning electron microcopy (SEM), and X-ray diffraction. X-ray absorption fine structure (XAFS) spectroscopy was performed on homogenous thin films to study local structural effects. The experimental results help to confirm regions on the phase diagrams and provide a suitable framework to perform theoretical modeling.

The chemistry of precipitation and metallic ordering in this alloy system was modeled with a theoretical technique known as the CALculations of PHAse Diagrams (CALPHAD) approach. This method couples fundamental information on the alloy energetics obtained from experimental and assessed thermochemical data to the used for designing alloys with engineering specificity with the help of the THERMO-CALC software application. The information collected in this study was used to model metastability and long-term stability for $\mathrm{Pu}-\mathrm{Ga}$, and $\mathrm{Pu}-\mathrm{Ga}-\mathrm{Fe}$ alloys by coupling THERMOCALC with DICTRA, a series of modules that allow the analysis of DIffusion Controlled TRAnsformations. The information can then be used to construct binary and ternary phase diagrams and TTT (Temperature-Time-Transformation) curves which serve as the foundation for understanding the physical and mechanical properties for this class of alloys. 


\section{INTRODUCTION AND MOTIVATION}

A primary concern in Pu-Ga alloys regards the poorly understood role of gallium and impurities of iron and nickel. Typically observed in intermetallic phases along triple points and grain boundaries, $\mathrm{Fe}$ and $\mathrm{Ni}$ are sufficiently soluble within the grains and may induce distortions and secondary phase formation in the nominal fcc (or d) structure. A second concern with these elements is the distribution and morphology of the secondary phases that are apparently highly sensitive to processing parameters. No known ternary phase diagram exists for the Pu-Ga-Fe and Pu-Ga-Ni systems.

Based on X-ray absorption fine-structure (XAFS) results for Pu-based alloys, it has been hypothesized that microscopic, localized lattice distortions and phase heterogeneities are present in these materials, and that their structure changes dramatically over time [1-3]. These studies have also suggested crystallographic positions for alloying and impurity atoms that were unexpected. Such results may have implications for any existing or future $\mathrm{Pu}-\mathrm{Ga}$ components.

Understanding the effects of impurities and local structure is important for modeling plutonium alloy behavior. The formation of undesirable phases and precipitates, the existence of intermetallics, and microstructural ordering are known to impact mechanical behavior. These phenomena also play an important role in microstructural evolution and long-term stability. As a result, there is a critical need to understand and verify the phase boundaries and thermodynamic parameters of plutonium-based alloys through theoretical modeling and validation by experimental techniques. In addition, data on the kinetics of second phase precipitation and ordering are lacking. Structural techniques such as XAFS spectroscopy were recently recognized in Science magazine [3] as being an essential in situ tool for characterizing the structural evolution of nuclear materials. Recent progress in theoretical modeling combined with state-of-the-art structural characterization techniques provide an ideal framework for investigating these materials.

\section{TECHNICAL APPROACH}

This project relies on strong coordination between experimental and theoretical efforts. The components of the experimental program (see Figure 1) are summarized as follows:

1) Sample preparation, synthesis, and processing.

2) Thermochemical measurements and analysis by differential scanning calorimetry (DSC).

3) Phase mapping and structural characterization by SEM, TEM and x-ray diffraction.

4) Element specific, short-range structural determination by XAFS and microXAFS [4]. 


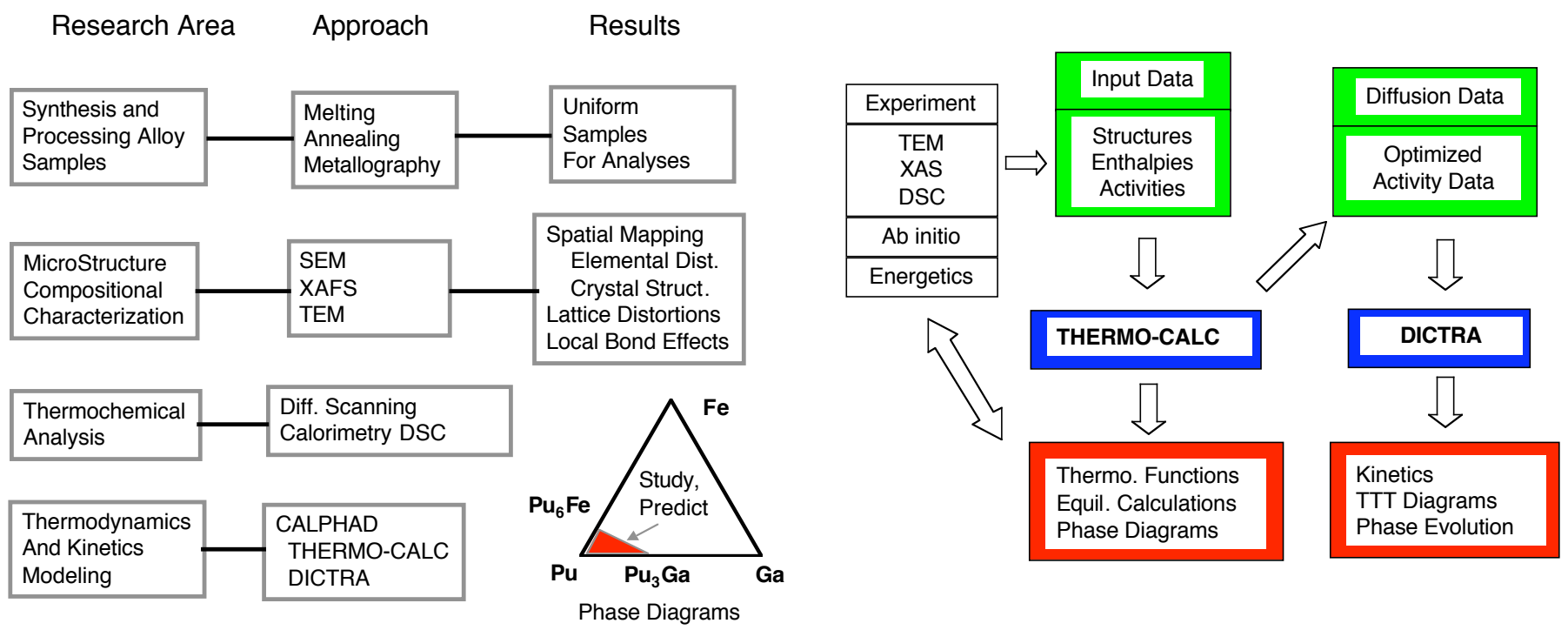

Figure 1. Overview of Proposed Research Plan

Figure 2. Multi-technique Approach to Thermodynamic Analysis

Bulk alloys of $\mathrm{Pu}-\mathrm{Ga}, \mathrm{Pu}-\mathrm{Fe}, \mathrm{Pu}-\mathrm{Ni}$, and $\mathrm{Pu}-\mathrm{Ga}-\mathrm{Fe}$ were synthesized at several $\mathrm{Ga}$ and $\mathrm{Fe}$ concentrations by melting techniques. The bulk alloy samples were analyzed by DSC and other metallographic analytical techniques. SEM, TEM, and X-ray diffraction were used to spatially map elemental and phase heterogeneity, and also to verify structure.

Additional samples were mechanically thinned for XAFS experiments to be measured in transmission mode. XAFS data can provide detailed structural information on the nature of lattice distortions (changes in bond lengths, coordination numbers) within the grain structure. The element specificity of XAFS allowed us to probe the environment of the $\mathrm{Pu}, \mathrm{Ga}, \mathrm{Fe}$, and $\mathrm{Ni}$ atoms separately within these structures, yielding valuable information on the alloying characteristics and lattice effects around the $\mathrm{Pu}, \mathrm{Ga}, \mathrm{Fe}$, and $\mathrm{Ni}$ atoms independently. The non-invasive nature of XAFS also enables the monitoring of alloy structure over time in order to study metastability and aging.

The theoretical component of this work utilized the so-called CALPHAD approach [5,6] supplemented by experimental and assessed information, and if necessary, by electronic-structure-based calculations [7,8] (see Figures 2 and 3). The CALPHAD (CALculation of PhAse Diagrams) approach introduced in the seventies by Larry Kaufman, including THERMO-CALC [5,6], involves the coupling of phase diagrams calculations for multi-component alloy systems with other forms of thermochemical inputs to address detailed thermodynamic questions which are relevant for this project, in particular:

- which phases form at a particular combination of temperature and composition?

- what are the proportions of the various phases?

- what heat treatments can be used to optimize structures and properties?

- at what temperatures do other phases appear or disappear by solid-state transformation? 


\section{Classical Thermodynamics}

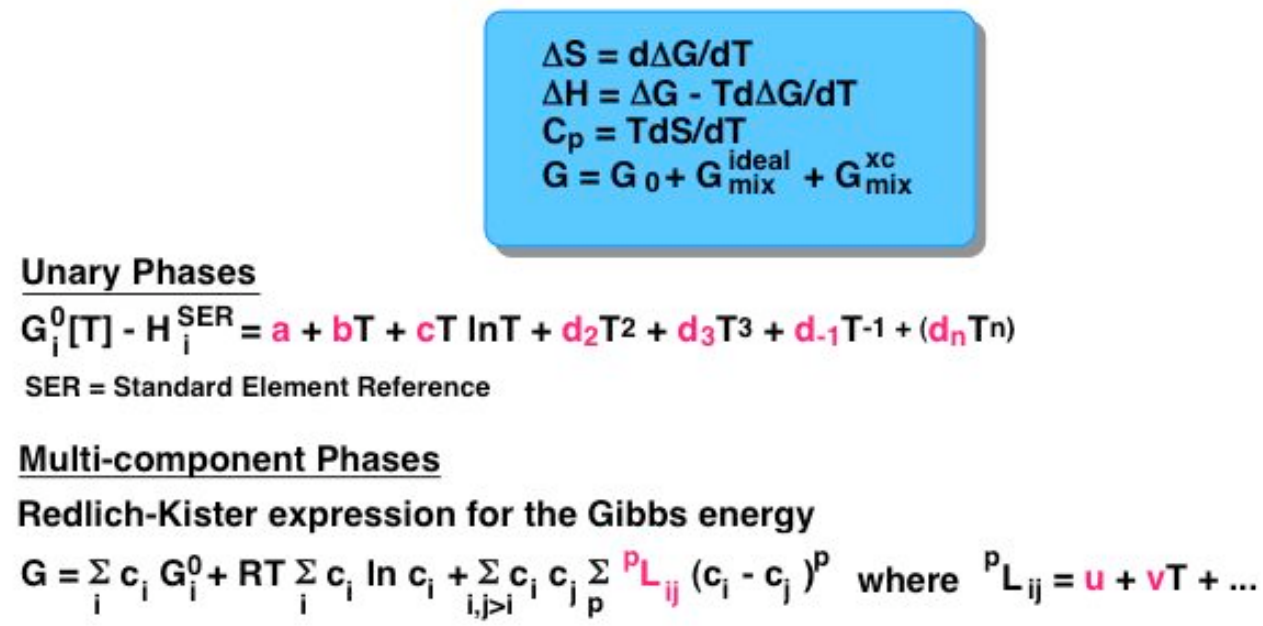

Figure 3. Thermodynamic Foundations of the CALPHAD modeling approach.

One of the major steps in the CALPHAD approach is the full characterization of a phase diagram, which includes all available thermodynamic data. Even in binary systems, difficulties often occur in answering all these questions solely by reference to an experimentally determined phase diagram. These difficulties arise from kinetic limitations on reaching equilibrium at low temperatures, and from inherent limitations on the accuracy of some of the available experimental techniques.

By supplementing the existing thermodynamic databank provided with the THERMO-CALC software application with experimental information collected from DSC, TEM, diffraction, and XAFS, a detailed analysis of $\mathrm{Pu}-\mathrm{Ga}$ alloys was undertaken with special emphasis on the role of additional solutes such as Fe on ordering, precipitation, and stability. This project builds on previous studies that addressed thermodynamic equilibrium and kinetics in restricted regions of phase and concentration space $[9,10]$ by using more elaborate thermodynamic modeling and a more accurate description of diffusion and kinetics.

\section{A. Alloy Synthesis.}

A small scale Pu melting furnace was refurbished from an existing thermal analysis instrument, brought online, tested, and implemented for bulk sample synthesis. The setup is housed in an Argon glovebox, and flushed with additional supply of ultra high purity Argon during operation. Melting was carried out in custom designed Tantalum crucibles (see Figure 4) using stochiometric amounts of electro-refined alpha $\mathrm{Pu}-239$ along with desired quantities of high purity (Alfa) Ga, Fe, and/or Ni metal. This apparatus provided controlled heating up to $1600{ }^{\circ} \mathrm{C}$ in a inert atmosphere, and allowed us to roughly monitor phase transitions via thermocouple response during product synthesis. Individual melting runs typically consisted of running at temperatures well above the liquidus for several hours to 
achieve adequate mixing, followed by isothermal equilibration in the solid state to achieve homogeneity and the desired end product (see Figure 5) Using this capability, we successfully synthesized bulk samples of $\mathrm{Pu}_{3} \mathrm{Ga}, \mathrm{Pu}_{6} \mathrm{Fe}$ and $\mathrm{PuNi}$. After studying the binary compounds, we synthesized the first ternary $\mathrm{Pu}-\mathrm{Ga}-\mathrm{Fe}$ alloys, and initiated characterizations of these alloys to validate theory.
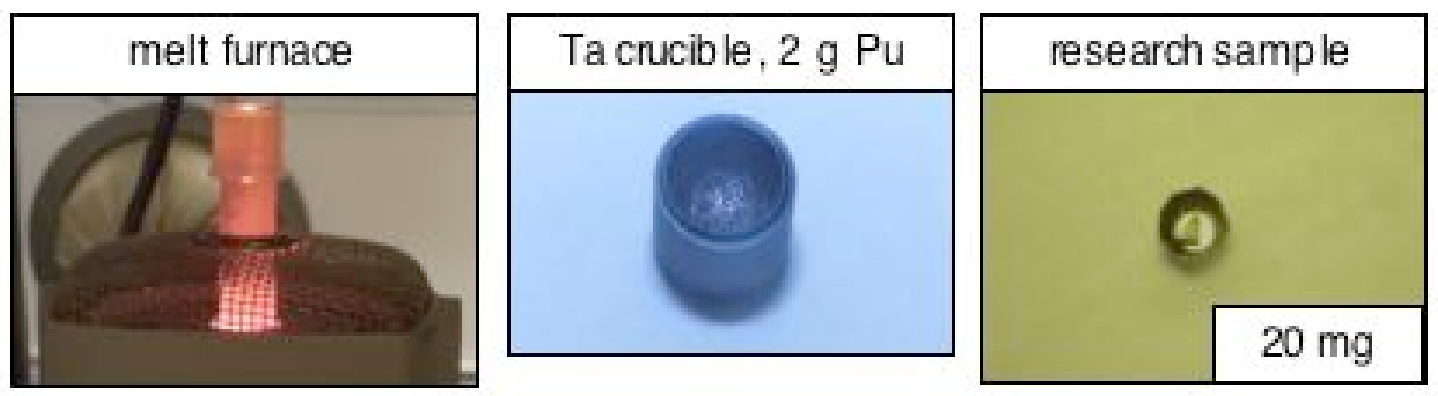

Figure 4. Components of small-scale melting capability for Pu Alloys.
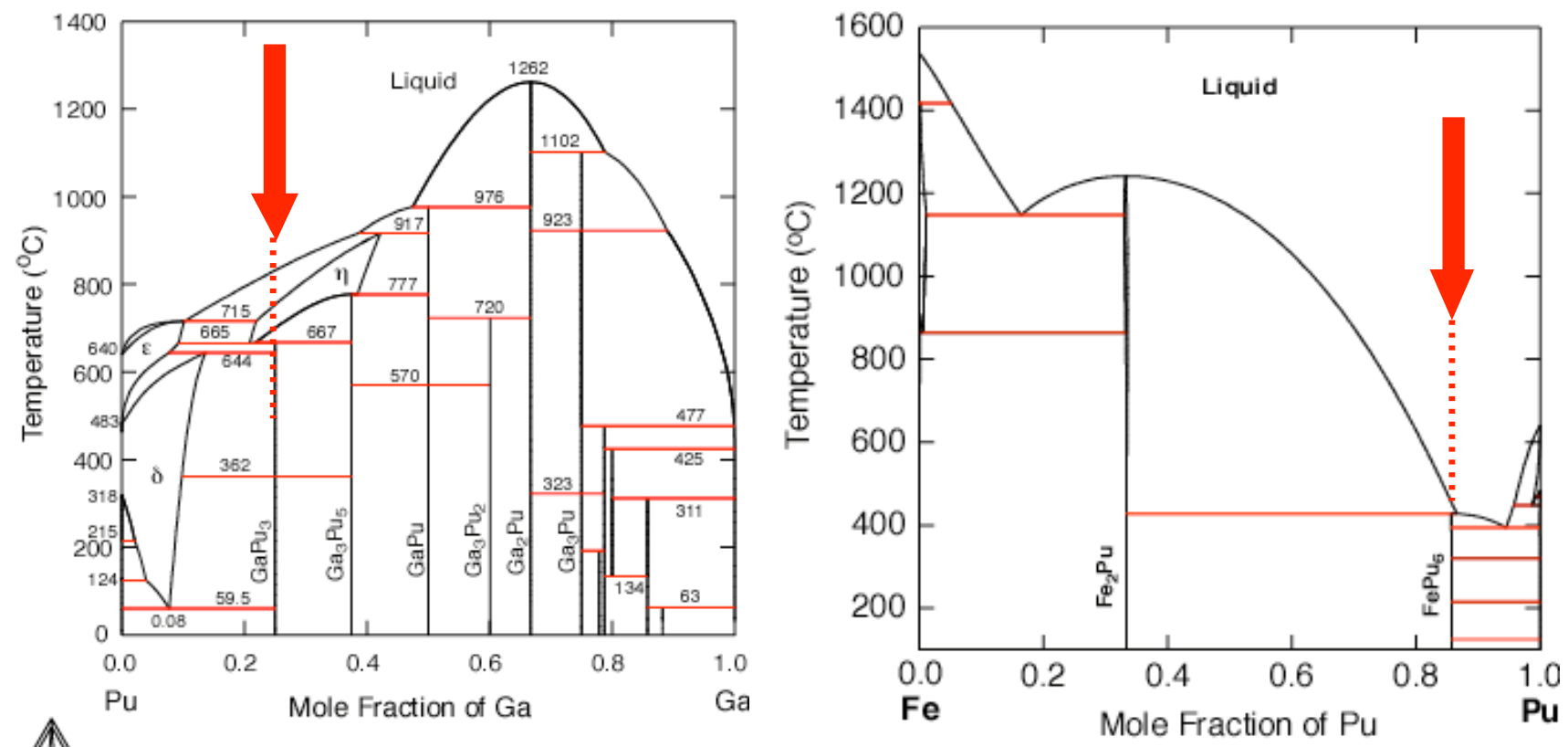

Figure 5. Phase diagrams for PuGa and PuFe systems (produced with CALPHAD) show the melt regions of interest.

\section{B. Structural Characterization: X-ray Diffraction, Optical, and SEM.}

X-ray diffraction (XRD), optical metallography, and scanning electron microscopy (SEM) were employed to study the structures of $\mathrm{Pu}_{3} \mathrm{Ga}$ and $\mathrm{Pu}_{6} \mathrm{Fe}$ and confirm the product syntheses. Specimens of each compound were cut and sectioned from the main product using a rotary cutter. XRD was 
performed on large pieces in reflection geometry. Optical metallography and SEM were carried out on smaller slices which had been mechanically polished and electrochemically cleaned.

XRD data were acquired and matched to and existing x-ray database for $\mathrm{Pu}$ compounds to confirm the structures. The raw data are shown in Figure 5. The results of XRD analyses revealed that the desired phases of $\mathrm{Pu}_{3} \mathrm{Ga}$ and $\mathrm{Pu}_{6} \mathrm{Fe}$ had been correctly synthesized with minimal contamination from other phases present.

Optical micrographs are shown in Figure 6. These images along with the XRD data and the SEM analyses show that the nominal $\mathrm{Pu}_{3} \mathrm{Ga}$ and $\mathrm{Pu}_{6} \mathrm{Fe}$ compounds were indeed synthesized. In both alloys, there appears to be some microstructural ordering, however, no extraneous phase were revealed by XRD. Additionally, the SEM analyses (not shown) revealed similar information to the optical data. SEM performed in an element selective mode also identified a minor amount of impurities $\left(\mathrm{PuO}_{2}\right.$, and Tantalum metal) which has apparently formed within the structure but had not alloyed with the Pu.

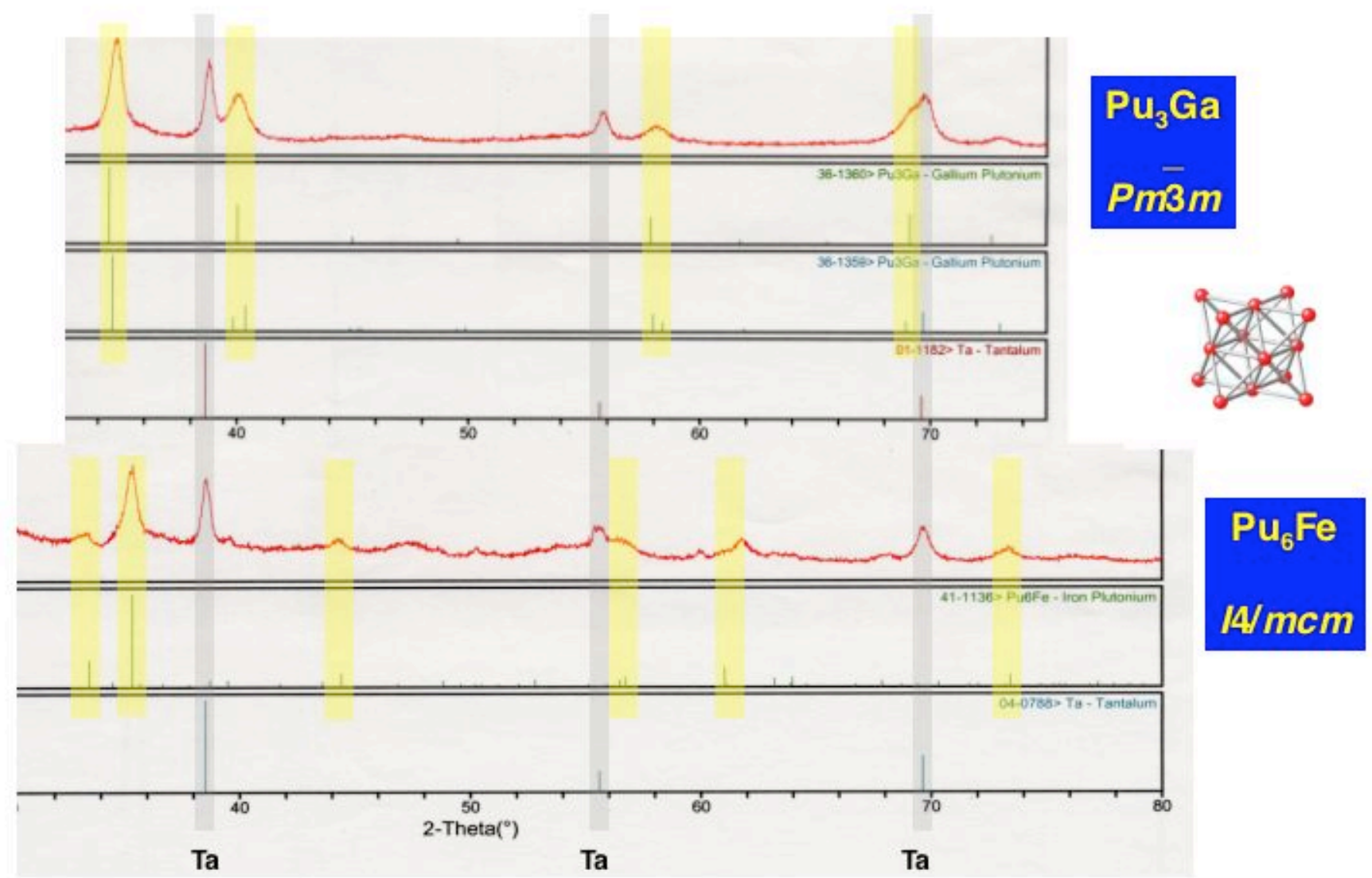

Figure 6. X-ray diffraction data for synthesized plutonium compounds $\mathrm{Pu}_{3} \mathrm{Ga}$ and $\mathrm{Pu}_{6} \mathrm{Fe}$. The peaks associated with Ta metal are present due to backscattering from the Ta holders. 


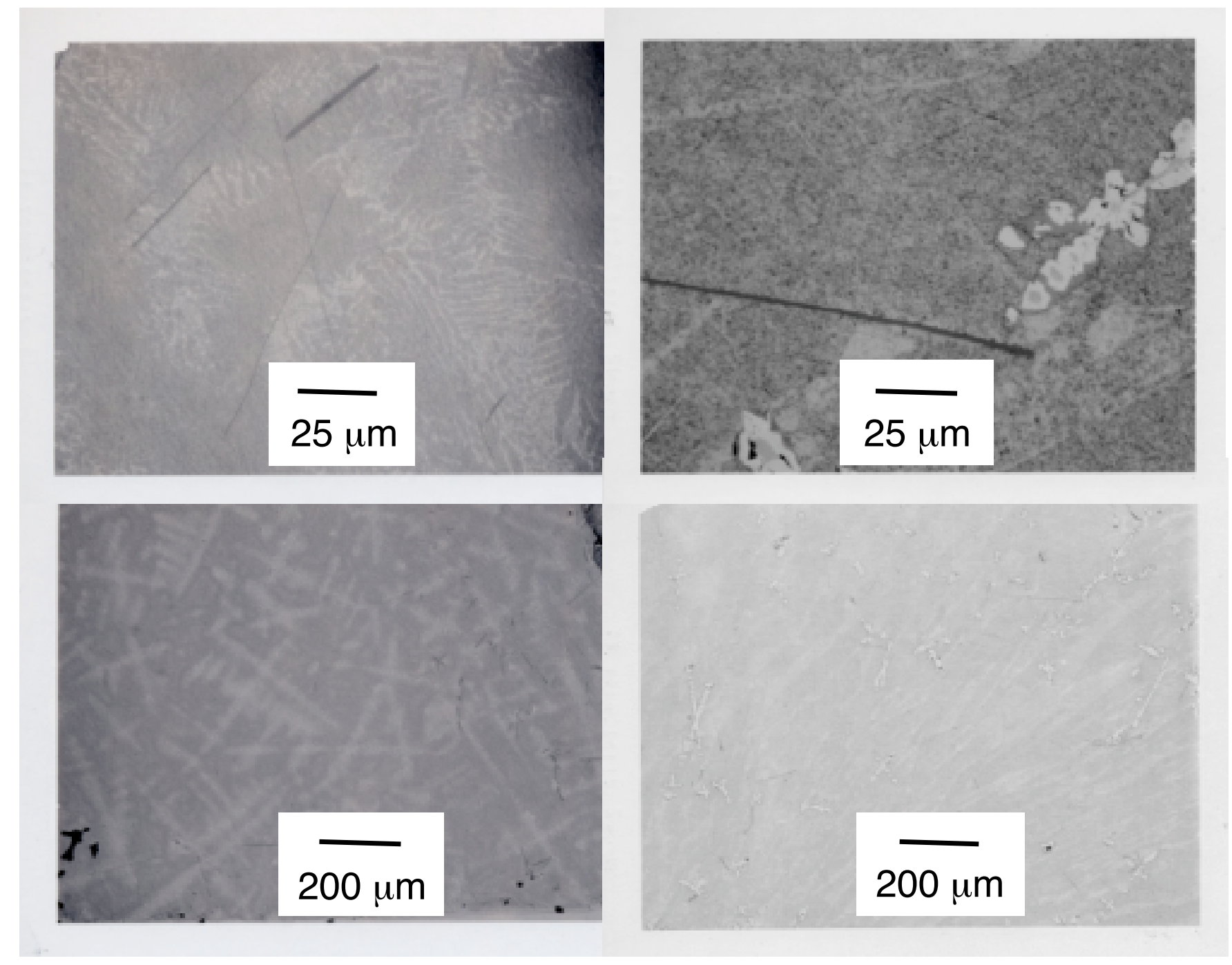

Figure 7. Optical micrographs for synthesized plutonium compounds $\mathrm{Pu}_{3} \mathrm{Ga}$ (left) and $\mathrm{Pu}_{6} \mathrm{Fe}$ (right). The dendritic structure in $\mathrm{Pu}_{3} \mathrm{Ga}$ results from micro-segregation upon cooling through the $\eta$ - phase.

\section{Structural Characterization: X-ray Absorption Fine Structure (XAFS) Spectroscopy}

XAFS was employed to probe the local environment of $\mathrm{Pu}, \mathrm{Ga}$, and Fe. Since XAFS is a local probe, it can identify aspects of the structure which are not seen by XRD. We developed XAFS instrumentation for variable temperature measurements $(10$ to $300 \mathrm{~K}$ ) on Pu. Because XAFS measures element specific local bonding, varying temperature allowed us to determine the structure and motion for the $\mathrm{Pu}, \mathrm{Ga}$, or Fe sites independently. This enabled the determination of vibrational properties of the local bond interactions. Our results revealed that the $\mathrm{Ga}$ sites experience stiffer local bonding relative to the $\mathrm{Pu}$ sites. This result could have significance as it relates to the lattice-stabilization in PuGa alloys. The details of this work and a related study can be found in References 11 and 12 . 


\section{Differential Scanning Calorimetry.}

The thermodynamics of phase transitions were measured using a TA instruments model 2920 DSC workstation. The instrument was run under continuous ultra-high purity argon flush using custommade Ta pans. Scan rates were typically $10{ }^{\circ} \mathrm{C} / \mathrm{min}$. Calibration was achieved under identical scan conditions using high purity $\mathrm{Al}, \mathrm{Zn}$, and In to achieve a multi-point calibration.

Pure alpha-Pu (50 mg piece) was analyzed to test the instrument response with $\mathrm{Pu}$ and benchmark theoretical simulations by CALPHAD. The results are shown in Figure 7. The integrated heats or enthalpies for each phase transition agree well with previous results. Also, the theoretical methodolgy can be validated by these numbers since CALPHAD is a semi-empirical iterative process (see later). The DSC workstation was used to obtain experimental data on the heats of formation for the synthesized stochiometric compounds $\mathrm{Pu}_{3} \mathrm{Ga}$ (Figure 8) and $\mathrm{Pu}_{6} \mathrm{Fe}$ (Figure 9). Approximately $50 \mathrm{mg}$ specimens of each compound were analyzed, and DSC scans were repeated several times to ensure reproducibility. The results of these measurements were input into CALPHAD in order to refine the numerical models. In some cases, there was a substantial correction required to the CALPHAD data.
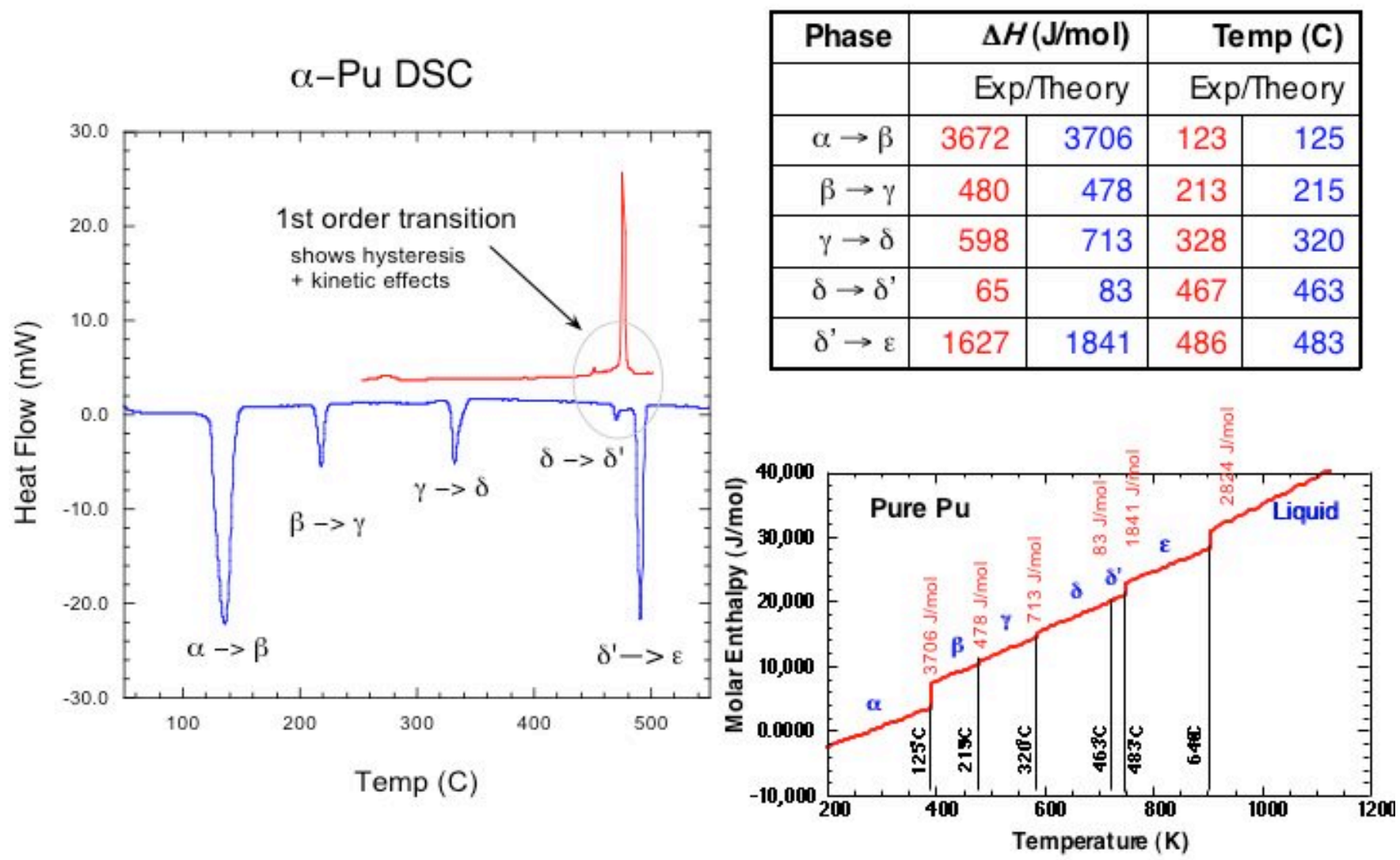

Figure 8. The enthalpies associated with plutonium phase transitions were measured by DSC for pure alpha-Pu (shown on left) and compared with CALPHAD theoretical simulations (lower right figure). The comparison illustrates the relationship between experimental and theoretical approaches. 


\section{Peritectoid Reaction at $675^{\circ} \mathrm{C}: \quad \mathrm{Pu}_{3} \mathrm{Ga} \rightarrow \mathrm{Pu}_{5} \mathrm{Ga}_{3}+\eta$}
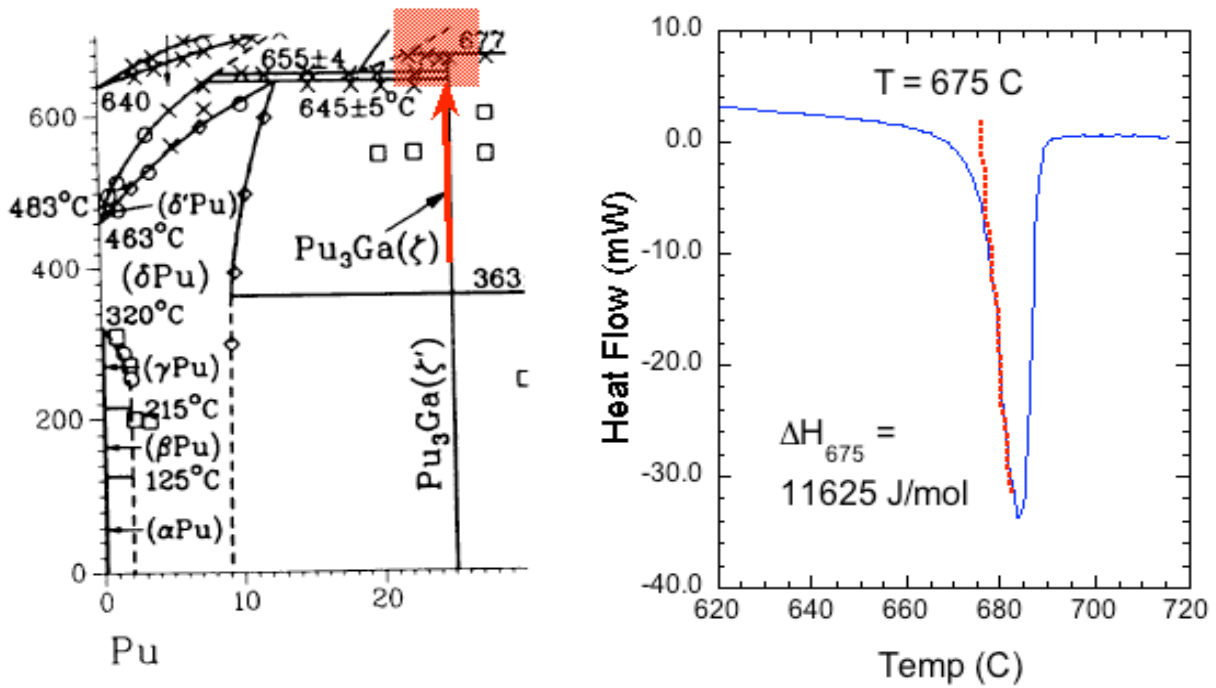

Figure 9. Phase diagram of peritectoid phase transition for $\mathrm{Pu}_{3} \mathrm{Ga}$ (left) and corresponding DSC experimental data trace (right) depicting enthalpy for this phase transition.

\section{Peritectic Reaction at $418^{\circ} \mathrm{C}$}

\section{$\mathrm{Liq}+\mathrm{Pu}_{6} \mathrm{Fe} \rightarrow \mathrm{Liq}$}
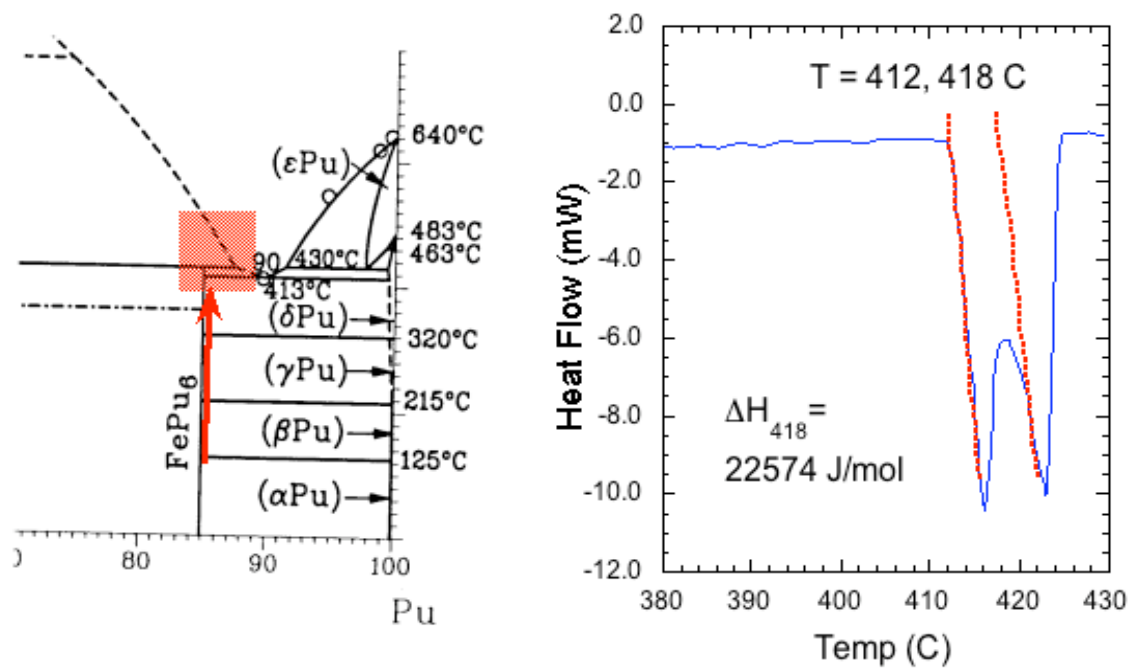

Figure 10. Phase diagram of peritectic phase transition for $\mathrm{Pu}_{6} \mathrm{Fe}$ (left) and corresponding DSC experimental data trace (right) depicting the enthalpy for this phase transition. 


\section{CALPHAD modeling.}

A complete assessment of the binary phase diagrams for $\mathrm{Pu}-\mathrm{Ga}$ and $\mathrm{Pu}-\mathrm{Fe}$ was completed in this project. The full composition assessments are shown in Figure 5 (see earlier). The Gibbs energies of the pure elements, the stoichiometric compounds and the solid solutions, and of the liquid phase have been evaluated by using the Parrot module (non-linear fitting tool) of the Thermo-Calc application software. For both alloys, the determination of all the thermodynamic functions allowed us to reconstruct the phase diagrams over the entire composition range. In the case of $\mathrm{Pu}-\mathrm{Ga}$, the low temperature behavior in the Pu-rich region was predicted. We confirmed the existence of a low-lying eutectoid between the $\alpha$-phase of $\mathrm{Pu}$, the $\delta$-based solid solution and the low temperature $\mathrm{Pu}_{3} \mathrm{Ga}$ compound at $59.5^{\circ} \mathrm{C}$ and 0.0778 mole fraction of Ga. This result shown in Figure 11 is similar to that suggested in the Russian phase diagram $\left(97^{\circ} \mathrm{C}\right.$ and 0.079 mole fraction of $\left.\mathrm{Ga}\right)$. Similar results were obtained for the Pu-rich part of the $\mathrm{Pu}-\mathrm{Al}$ phase diagram.
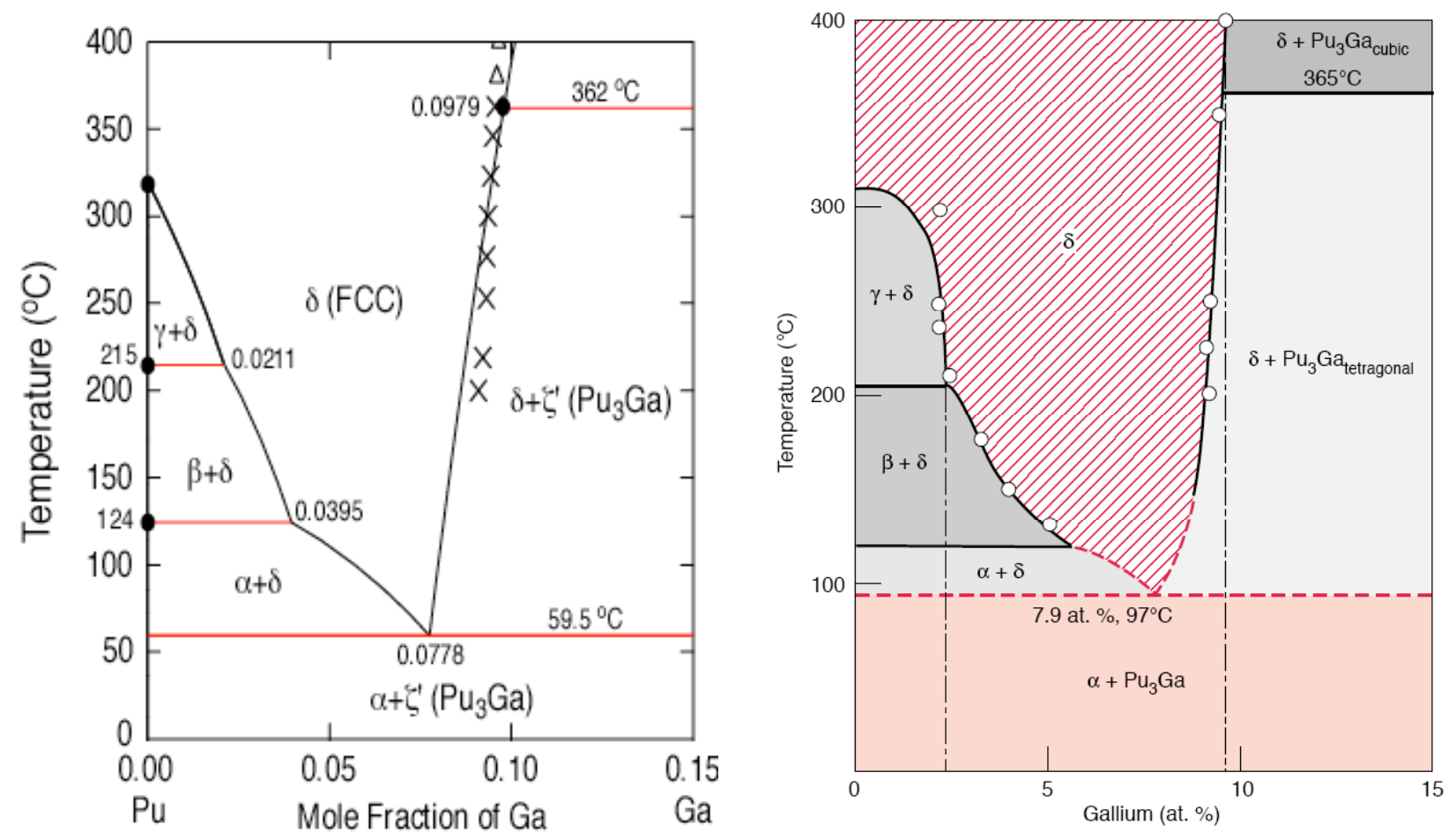

Figure 11. Comparision of CALPHAD simulation (left) and the relatively recent phase diagram reported by Chebotarev et al, 1990, (Reference 13). These results validate one another and are different from the phase diagram of Ellinger et al, 1964, (Reference 14) which had placed the $\delta$ phase region boundary as extending down to $0^{\circ} \mathrm{C}$ without the eutectoid at $\sim 97^{\circ} \mathrm{C}$.

The theoretical results of heats of transformation (six transformations up to the liquid phase) for pure $\mathrm{Pu}$ were also successfully compared with the results of DSC measurements. These encouraging 
results demonstrated the operation of the DSC apparatus and that full self-consistency between experiment and theory could be achieved for the analyses performed on the alloys.

Along with the PuGa and PuFe assessment, a full assessment of the Fe-Ga binary phase diagram was performed to provide the required parameters and energetics for ternary modeling. This allowed us to predict and construct the first-ever ternary $\mathrm{Pu}-\mathrm{Ga}-\mathrm{Fe}$ phase diagram. We used isothermal sections of this diagram in order to select alloy compositions for the experimental validation (see Figure 12).
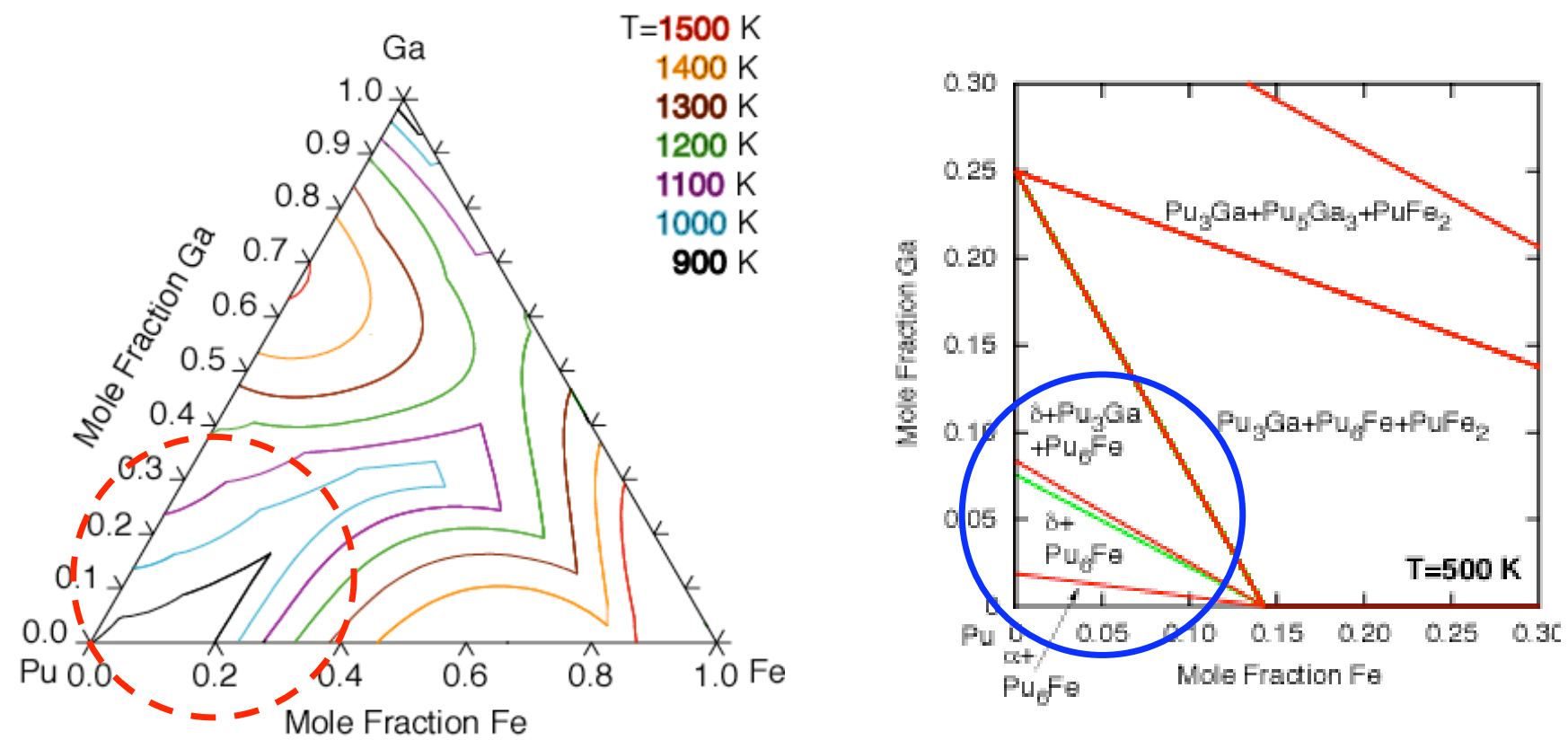

Figure 12. Theoretical Assessment for the ternary Pu-Ga-Fe system (on left) displaying isothermal solid-liquid concentration boundaries (liquidus lines). The 2 dimensional figure on the right represents the $\mathrm{Pu}$-rich region phase behavior at low temperature, $500 \mathrm{~K}$.

\section{E. TECHNICAL OUTCOME}

This work is aligned with the DOE's investment in programmatic and fundamental aspects of nuclear science (i.e., defense applications and actinide metallurgy). The project yielded valuable information concerning the role of $\mathrm{Ga}, \mathrm{Fe}$, and other solutes (or impurities) on the thermodynamics, secondary phase formation, and local structural effects in $\mathrm{Pu}-\mathrm{Ga}$ alloys, and enabled the construction of ternary phase diagrams that were previously undetermined.

In addition, the thermodynamic database we developed will be essential for studying kinetics of phase decomposition reactions in the future. Our coupled experimental-theoretical approach yielded a comprehensive thermochemical database for the $\mathrm{Pu}-\mathrm{Ga}-\mathrm{Fe}$ and related ternary systems. We made important modifications to the binary and ternary enegetics based on new calorimetry data, expanded our simulations of the ternary $\mathrm{Pu}-\mathrm{Ga}-\mathrm{Fe}$ system, and calculated $\mathrm{Pu}-\mathrm{Ga}$ Martensitic transformation kinetics, providing new mechanistic insight into the nature of $\mathrm{Pu}$ phase transformations. 
The long-term benefit of this work is the development of state-of-the-art experimental and theoretical tools for studying actinide alloys. One important example is the development of Pu XAFS and its ability to determine elastic properties (e.g., bulk modulus)--a result which was serendipitous (described in detail in Refs. 11, 12. The results and research skills developed from this research form a basis for future predictive and experimental work in order to assess the impact of solutes on $\mathrm{Pu}$ alloy phase and mechanical behavior. This work also forms a scientific foundation for studying important aspects of metal dynamics and aging (i.e., other defense areas), and is applicable to other materials such as uranium alloys.

\section{REFERENCES}

[1] L. E. Cox, R. Martinez, J. Nickel, S. D. Conradson, and P.G. Allen, "Short-range Atomic Structure of 1 wt\% Ga Delta-Stabilized Plutonium X-ray Absorption Fine Structure Spectroscopy”, Phys. Rev. B, 51, 751-755, 1995.

[2] S. D. Conradson, "Application of X-ray Absorption Fine Structure Spectroscopy to Materials and Environmental Science”, Appl. Spectr., 52, A252-A279, 1998.

[3] S. Drell, R. Jeanloz, and B. Peurifoy, "Maintaining a Nuclear Deterrent Under the Test Ban Treaty", Science, V283, 1119-1120, 1999.

[4] S. R. Sutton, S. Bajt, J. Delaney, D. Schulze and others, "Synchrotron XRF MicroprobeQuantification and Mapping of Mixed Valence State Samples Using Micro-XANES”, Rev. Sci. Inst., 66, 1464-1467, 1995.

[5] A. P. Miodownik, "Phenomenological Calculations of Phase-equilibria: the CALPHAD Approach", in NATO-ASI Proceedings, Series B: Physics, V319, eds. P. E. A. Turchi and A. Gonis (Plenum Press, NY, 1994), p. 45-79.

[6] N. Saunders and A. P. Miodownik, "CALPHAD (Calculation of Phase Diagrams): A Comprehensive Guide”, Pergamon Materials Series, V1, edited by R. W. Cahn (Pergamon, Elsevier Science Ltd., Oxford, 1998).

[7] P. E. A. Turchi. "Electronic Theories of Alloy Phase Stability", in "Intermetallic Compounds: Principles and Practice", eds. J. H. Westbrook and R. L. Fleischer (John Wiley \& Sons, Ltd., New York, 1995), V1, pp. 21-54.

[8] P. E. A. Turchi, A. Gonis, et al. "Correlation Effects on Stability in Pu Metal and its Alloys", Proc. of the Int. Workshop on "Electron Correlations and Materials Properties", edited by A. Gonis, N. Kioussis, and M. Ciftan (Kluwer Academic/Plenum Publishers, New York and London, 1999), p.53137.

[9] P. H. Adler and G. B. Olson, "Thermodynamics and Kinetics of $\alpha \rightarrow \delta$ Martensitic Transformation in Pu Alloys", Metall. Trans. 19A, 2705-11, 1988. 
[10] P. H. Adler, "Thermodynamic Equilibrium in the Low-solute Regions of Pu-group IIIA Metal Binary Systems", Metall. Trans. 22A, 2237-46, 1991.

[11] P. G. Allen, A.L. Henderson, E. R. Sylwester, P.E.A. Turchi, T.H. Shen, G.F. Gallegos, and C.H. Booth, " Vibrational properties of Ga-stabilized delta-Pu by Extended X-ray Absorption Fine Structure," Phys. Rev. B, 65, 214107, 2002. UCRL-JC-146442.

[12] E.J. Nelson, K.J. Blobaum, M.A. Wall, P.G. Allen, A.J. Schwartz, and C.H. Booth, " Local Structure and Vibrational Properties of alpha'-martensite in Ga-stabilized delta-Pu." Phys. Rev. B, 67, 224206, 2003. UCRL-JC-151541.

[13] Chebotarev, N. T., V. S. Kurilo, L. F. Timofeeva, M. A. Andrianov, and V. V. Sipin.

VANT, Ser. Materialovedenie i noviie materialii, 3 (37): 20, 1990.

[14] Ellinger, F. H., C. C. Land, and V. O. Struebing. J. Nucl. Mater. 12: 226, 1964. 